\title{
BIM AND GIS INTEGRATION FOR INFRASTRUCTURE ASSET MANAGEMENT: A BIBLIOMETRIC ANALYSIS
}

\author{
M. Garramone ${ }^{1 *}$, N. Moretti ${ }^{1}$, M. Scaioni ${ }^{1}$, C. Ellul $^{2}$, F. Re Cecconi ${ }^{1}$, M. C. Dejaco ${ }^{1}$ \\ ${ }^{1}$ Dept. of Architecture, Built Environment and Construction Engineering, Politecnico di Milano, via Ponzio 31, 20133 Milano, Italy \\ - (manuel.garramone, nicola.moretti, marco.scaioni, fulvio.rececconi, mario.dejaco)@ polimi.it \\ ${ }^{2}$ Dept. of Civil, Environmental and Geomatic Engineering, University College London, Gower Street, London, WC1E 6BT UK - \\ c.ellul@ucl.ac.uk
}

KEY WORDS: BIM, GIS, Asset Management, digitisation, information management, infrastructure

\begin{abstract}
:
The integration of Building Information Modelling (BIM) and Geographical Information Systems (GIS) is gaining momentum in digital built Asset Management (AM), and has the potential to improve information management operations and provide advantages in process control and delivery of quality AM services, along with underlying data management benefits through entire life cycle of an asset. Work has been carried out relating GeoBIM/AM to buildings as well as infrastructure assets, where the potential financial savings are extensive. While information form BIM maybe be sufficient for building-AM; for infrastructure AM a combination of GIS and BIM is required. Scientific literature relating to this topic has been growing in recent years and has now reached a point where a systematic analysis of current and potential uses of GeoBIM in AM for Infrastructure is possible. Three specific areas form part of the analysis - a review of BIM and Infrastructure AM and GIS and Infrastructure AM leads to a better understanding of current practice. Combining the two, a review of GeoBIM and Infrastructure AM allows the benefits of, and issues relating to, GeoBIM to be clearly identified, both at technical and operational levels. A set of 54 journal articles was selected for in-depth contents analysis according to the AM function addressed and the managed asset class. The analysis enabled the identification of three categories of issues and opportunities: data management, interoperability and integration and AM process and service management. The identified knowledge gaps, in turn, underpin problem definition for the next phases of research into GeoBIM for infrastructure AM.
\end{abstract}

\section{INTRODUCTION}

Asset Management (AM) is a primary organisational function for realising value from assets, balancing risk, costs and opportunities (ISO, 2014). This discipline is not new and in the last 30 years, it has been defined, standardised and adapted to different fields, providing support for the operation and management of assets and ensuring that improved asset performance and higher quality decision making helps to achieve business objectives (Amadi-Echendu et al., 2010). AM is the function that connects the core business of an organisation to the infrastructure (digital and physical) that must be operated for its success.

Despite underpinning the life cycle of a physical entity in terms of technical, financial and user-oriented performance, AM is a relatively late adopter of the digital innovation that could be exploited to better face the current challenges in the Architecture, Engineering, Constructions and Operations (AECO) sector. However, in recent years management of the Built Environment (BE) is undergoing a revolution due to the digital transformation that is affecting the management tools, processes and the definition of the asset itself (Parn and Edwards, 2019). Additionally, the physical asset is increasingly included in the set of information, processes and software platform that are employed from the design to the use/operational phase of its life cycle: the digital environment, resulting in integrated digital/physical systems. This dynamic can be defined as the digitisation of management of the built environment and is shaping a new paradigm in AECO (Saxon et al., 2018). The integrated digital/physical asset is characterised both by the performance related to the functioning of the physical elements (e.g. the comfort performance of an indoor space of a facility, the load capacity of a bridge or the water flow rate of a section in a water supply system etc.) and by the services that can be delivered through its digital replica.

Data relating to the asset and the surrounding built environment can be sourced from a wide range of disparate sources - sensors, 3D models, engineering drawings, maintenance reports and schedules, financial reports, time-tables, personnel details and more. Location - where asset data is situated to in 3D space provides perhaps the most important approach to integrating (linking) this new digital data, allowing, for example, sensor data for room temperature to be examined in conjunction with occupancy data for the room. Two location-enabled tools are at the forefront of the management of the new complexity of the digital BE: Building Information Modelling (BIM) and Geographic Information Systems (GIS).

The British Standards Institute (BSI) defines BIM as "the management of information flows along the life cycle of the asset through the use of digital modelling" (BSI, 2018). Therefore, adopting a BIM approach means implementing a set of digital processes, empowered by digital tools, procedures, methodologies, furthering efficiency of the information exchange and collaboration among parties. GIS are defined as a "computerbased information system that enables capture, modelling, storage, retrieval, sharing, manipulation, analysis, and presentation of geographically referenced data" (Worboys and Duckham, 2004). Very broadly, GIS can provide high-level information about the context of an asset and about the asset itself and its operation, covering an extended geographical area, BIM focuses more on structural and engineering detail for specific projects (Ellul, 2018). From the AM perspective, the potential in the employment of these two approaches can be found in the

\footnotetext{
Corresponding author
} 
information and process management capabilities offered, enabling the improvement not only in the design and construction phase, but also of operations in the use phase (Dixit et al., 2019). Linking the data provided by GIS and BIM can underpin the development of an integrated digital model of the built asset, supporting advanced information management in the digital built environment.

This integration is broadly defined as "GeoBIM" and overcoming process and information management issues across different stages of the assets' life cycle (Ellul et al., 2018). GeoBIM as a topic has been subject of study at the international level in recent years (e.g. Noardo et al., 2019, Wang et al. 2019). The implementation of the GIS/BIM integrated approaches to address multidisciplinary problems in $\mathrm{AM}$ is, therefore, gaining momentum. Additionally, while BIM on its own - with its focus on detail of, in particular, indoor environments - could potentially provide information for AM of buildings, GeoBIM integration is particularly important for infrastructure - where an asset could be located over a large area, at mapping scales more suited to GIS, with engineering detail from BIM.

While meta-studies have been carried out reviewing technical approaches to BIM and GIS integration (e.g. (Wang, 2019) a systematic analysis of the scientific literature in GIS/BIM integration for $\mathrm{AM}$ is missing, in particular in the context of infrastructure, and with AM rather than GIS or BIM its main focus. This article provides a systematic review of the bibliography, collected from Web of Science (WoS) and Scopus, identifying trends, issues and opportunities relating to the use of GeoBIM for infrastructure AM. This, in turn, yields a better understanding of the knowledge gaps to be addressed in a GeoBIM for infrastructure AM research agenda.

\section{METHODS}

The research was conducted in early April 2020 following the standard process of systematic literature review (Moher et al., 2015): identification, screening, eligibility and inclusion. The first step concerns the definition of the research keywords to select a set of articles corresponding to the boundaries of the research field in BIM, GIS and the integration of the two for infrastructure AM. The Scopus and WoS databases have been queried with keywords represented in Figure 1. The use of wild characters and the boolean operators ("AND" and "OR") resulted in 226 results from Scopus and 219 from $\mathrm{WoS}^{1}$.

((geographic information system* OR gis)

$\mathrm{OR}$

(building information modelling OR building information modeling OR bim)) AND

(asset* management OR am) AND

infrastructure*

Figure 1. Search terms used in Scopus ("Article title, Abstract, Keywords" field) and in WoS ("Topic" field).

The results have then been further filtered to remove references not relevant for the scope of the research (filtering by subject area), and by category, again excluding those not related to the scope of the research (e.g. medicine, art, chemistry, etc.). This step resulted in the identification of 181 (Scopus) and 179 (WoS) references. Once the sample was defined, bibliometric analyses were carried out and historical data trends and network analysis has been obtained, using the $\mathrm{R}$ package Bibliometrix, (Aria and Cuccurullo, 2017), version 2.3.2 dated 23/11/2019. The sample

\footnotetext{
${ }^{1}$ As noted above, this search is specifically AM focussed - i.e. papers relating to IFC and CityGML interoperability or to other GeoBIM applications are excluded.
}

was then reduced to a number of papers appropriate for contents analysis. To achieve this, references have been:

1. filtered by year, considering the references published in between 2013 and 2020, a period in which a clear increasing in the literature production can be identified (after 2013 more than 10 articles per year have been published in the Scopus database). Subtotal results obtained are 108 (Scopus) and 121 (WoS);

2. refined by document type. In order to reduce the complexity of the databases, in this research only the journal articles in English were considered. Subtotal results obtained are 40 (Scopus) and $71(\mathrm{WoS})$;

3. refined according to an in-depth review of title and abstract, selecting only the documents with high research relevance. Subtotal results obtained are 31 (Scopus) and 46 (WoS);

4. refined by removing duplicates and merging the datasets obtained from the two databases.

The final set of 54 articles was then categorised according to the type of approach and technology adopted in AM: BIM, GIS, the integration of the two and the AM function addressed. A similar classification has been carried out considering the asset class managed. These meta and content analyses enabled the identification of the knowledge gaps to be addressed in a research agenda in GeoBIM for infrastructure AM.

\section{RESULTS}

\subsection{Bibliometric analysis}

Considering the annual scientific production represented in Figure 2 an increasing interest in the use of BIM and GIS for infrastructure AM is evident in recent years. The annual growth rate, excluding the year 2020 (not yet completed at the time of the research) is $12,99 \%$ (Scopus) and 9,05\% (Web of Science).

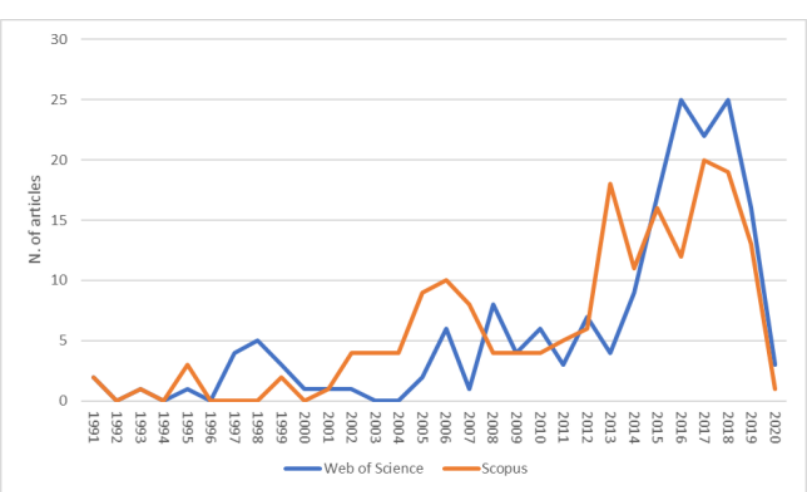

Figure 2. Published scientific literature (1991-2020)

Since the first published article in Scopus, a first peak can be seen around 2006, when the annual summary of the scientific production in both databases exceeded 15 articles. However, the first significant increase is registered after 2004, when the sum of the publications in both databases started to be almost always around 10 documents, with a peak in 2006. After 2013 an even more relevant increase is shown.

In order to highlight how the research field is structured, some network analyses have also been carried out. Authors' keywords were considered with the number of nodes of 25 and a minimum edge of 2. Figure 3 shows the most influential terms. The larger 
size of the circle represents the greater occurrence and the links describe the strength of the co-occurrence of terms. The centrality of AM and the big dimensions of BIM and GIS clusters are to be expected as they are the terms used to build up the query.

Examining the links, is clear that AM is supported by GIS or BIM tools, but as yet a strong link between the two tools cannot be identified, indicating a gap to be further investigated.

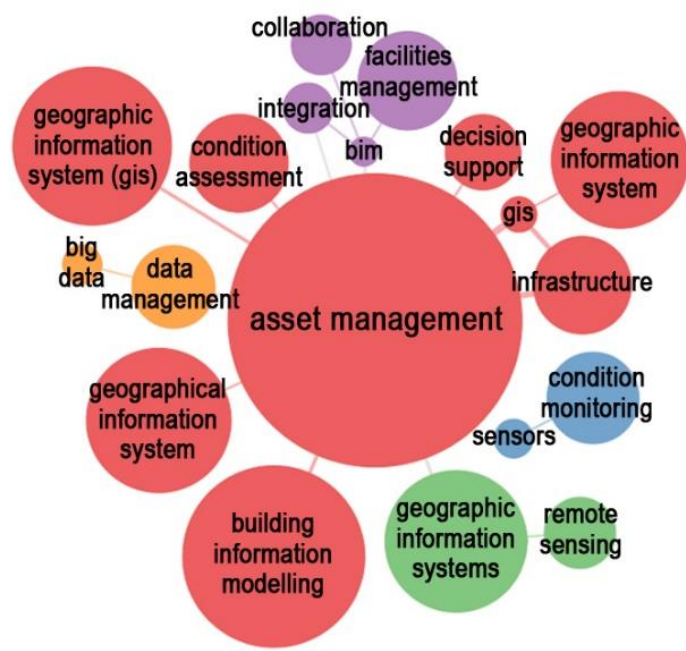

Figure 3. Keywords co-occurrence network (Scopus database)

Moreover, Figure 3 highlights five clusters of keywords primarily indicating the link between the digital tools and the AM functions, suggesting the link between GIS, condition assessment and decision making (red cluster); sensors and condition monitoring (blue cluster); remote sensing and GIS (green cluster), data management and big data (orange cluster); BIM and Facility Management (FM) (purple cluster). Figure 4 shows the same analysis for WoS. The clusters are similar, although more importance (dimension of the circle) given to BIM compared to GIS and, again a link appears between the AM functions and the digital tools, especially concerning the purple cluster indicating a relationship among BIM, big data, FM and the blue cluster, connecting the GIS domain to infrastructure AM.

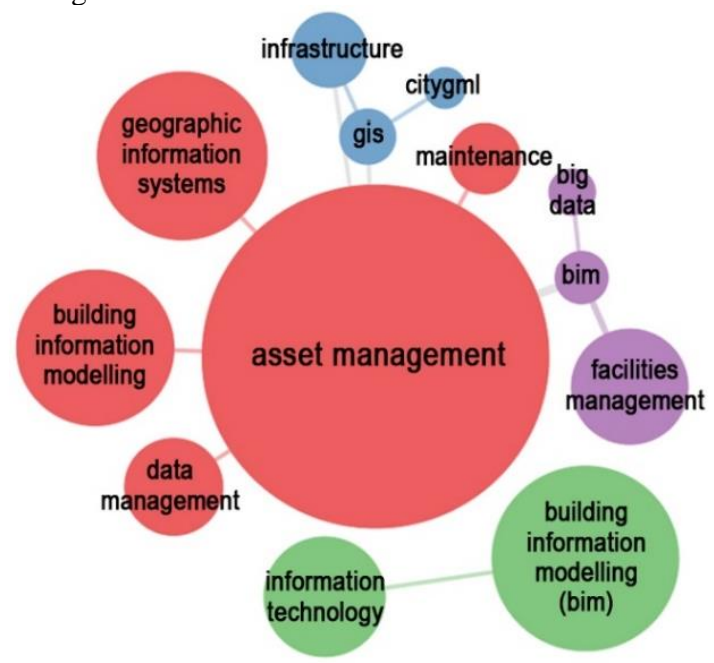

Figure 4. Keywords co-occurrence network (WoS database)

Social structure (Figure 5) was analysed through the countries' collaboration network with a number of nodes of 20 and a minimum edge of 1 . As shown in Figure 5, the social structure in Scopus is slightly different from the one obtained from WoS. In fact, Scopus presents four clusters, corresponding approximatively to four main geographic areas, led by USA, UK and Australia. A situation confirmed by the same analysis carried out on Scopus references, though to the most productive countries already identified in Scopus database, Italy and China can be added. Moreover, in this case, the five clusters do not correspond to any homogeneous geographic areas.

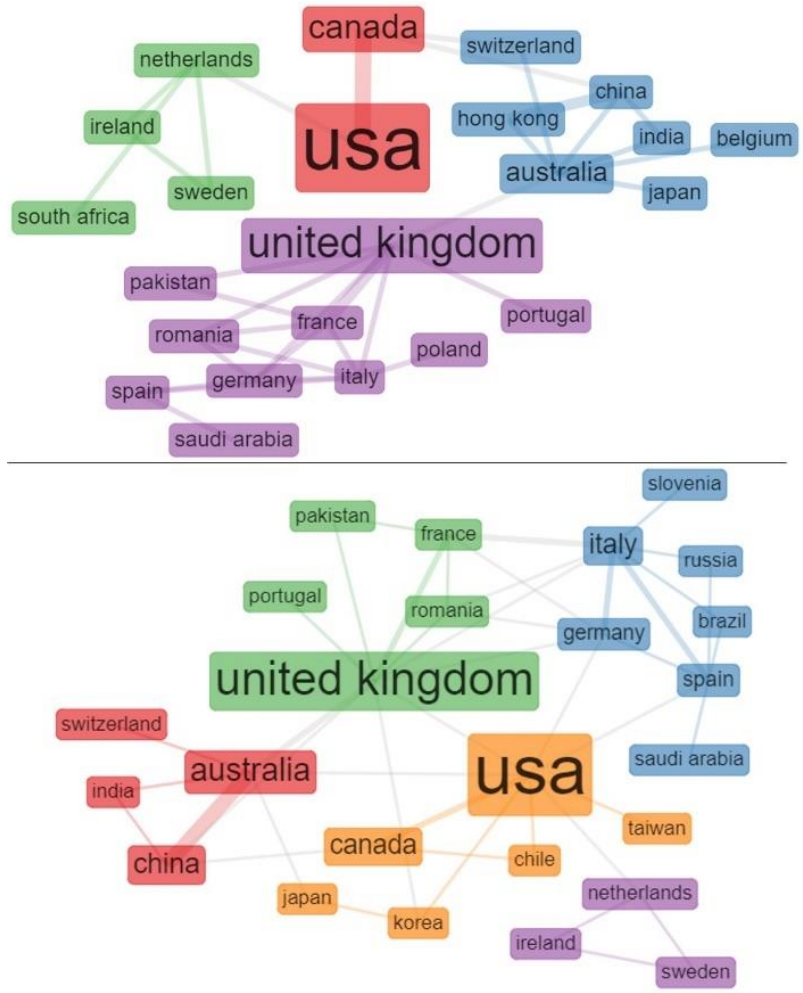

Figure 5. Collaboration Network, by Countries (Scopus at the top and WoS at the bottom)

In order to allow comparison, the analysis described above has been carried out on the whole dataset (181 references in Scopus and 179 in WoS). The following results related to the 54 journal articles obtained after the further filtering steps described in Section 2 (steps 1 to 4). Figure 6 represents the results of the filtering before merging the two datasets, highlighting a higher presence of articles in the WoS database, and after merging them. In line with the keywords co-occurrence network, most of the articles are developed using or BIM or GIS with a much smaller percentage relating to the use of both the tools. The final selection consists of 16 articles BIM-oriented, 29 articles GIS-oriented and 9 articles with BIM-GIS integration and Infrastructure Asset Management, for total.

\subsection{BIM for Infrastructure Asset Management:}

The first set of references considered concerns the use of the BIM approach for infrastructure AM. To date, the BIM approach is mostly employed during the design and construction phases, rather than in operations and facilities management (Hassan Ibrahim, 2013) despite representing an added value for the information management during the latter (Bosch et al. 2015, Parlikad and Catton 2018).

3.2.1 Information management and uncertainty: An accurate BIM model can support operation and maintenance through the integration of the existing AM system and the model data (Heaton et al., 2019). Additionally, it can provide great advantages in the re-baselining process during AM operations, through a periodic four-step workflow based on collecting, verifying, processing and updating of asset data (Abdirad and 
Dossick, 2020). In fact, according to Love et al. (2015) the development of a BIM model for asset management should start at the outset of the project, considering the whole asset life-cycle in order to facilitate the information exchange and across the several stages of the management process, supporting strategic decision making and reducing uncertainty in asset management (Krystallis et al., 2016). Moreover, Love et al. (2017b) further confirm this position, analysing the cost performance of 16 rail projects, demonstrating that the implementation of BIM can improve cost certainty during the construction process. The implementation of BIM for infrastructure AM also allows better data integration: combining various temporal data categories for two bridges, Zhang et al. (2018) proposed a 4D-based model for supporting predictions and driving maintenance activities.
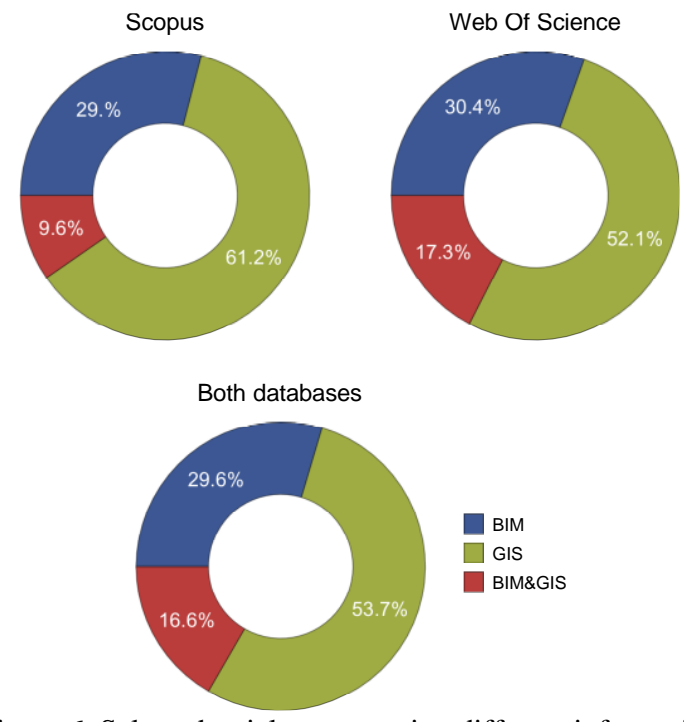

Figure 6. Selected articles concerning different information management approaches in WoS, Scopus and both databases.

3.2.1. Process integration: Process management is a crucial issue in BIM implementation for infrastructure AM. In rail projects, for instance, the digital models are large and complex and should be accompanied by advanced AM processes, able to leverage the potential of the digital models and of the related nongraphical information (Dell'Acqua et al., 2018). Moreover, using BIM applications during planning and delivery phases of rapid transit projects enables a more efficient operation and maintenance through integration with asset-monitoring systems (Saldanha, 2019).

\subsubsection{Asset performance monitoring}

AM cannot exist without an effective monitoring and control system. Therefore, Delgado et al. (2017) propose a BIM-based approach for structural performance monitoring in order to visualize, manage, interpret and analyse data collected by structural health monitoring systems

3.2.3. Other approaches: Alternatives to BIM include the development of a relationally integrated value network (RIVANS) for total asset management (TAM) (Smyth et al., 2017). Additionally, some authors developed frameworks and workflows considering infrastructure case studies (electrical systems, rail transport and bridges). For instance, Love et al. (2016) starting from the issues in omissions in as-built CAD documentation happening in traditional design and management approaches and from the potential of the BIM tools, proposed a System Information Model (SIM) for digital asset management of electrical infrastructures.

\subsection{GIS for Infrastructure Asset Management}

As shown in Figure 6, the majority of the results obtained relate to the use of GIS for infrastructure AM. This trend could be explained by two reasons: firstly, GIS was developed in the ' $60 \mathrm{~s}$, and thus it has been evolving from a specialist technology to an interdisciplinary tool for more than 50 years (Bishop and Grubesic, 2016); secondly, GIS is used for spatial data and analysis over large geographical extends, and to assess infrastructure it is necessary to visualize how they relate to their surrounding environment (Zhao et al., 2019).

3.3.1. Risk management: Risk assessment, and disaster planning and mitigation is a major topic in both transportation and utility infrastructure AM. Different GIS approaches are used to assess transportation system vulnerabilities (Kim et al., 2013), densely populated urban areas (Sherly et al., 2015) and the interactions between different infrastructure networks in order to develop an integrated assessment of service vulnerabilities (Inanloo et al., 2016). Climate change and urbanization have led to the development of frameworks for disaster prevention (Nakamura et al., 2019), frequency and severity (Kruel, 2016). For instance, Espada et al., (2015) proposed a spatial framework for critical infrastructure systems focused on climate adaptation and flood mitigation. Through the construction of thematic maps of vulnerability and damage (Scaini et al., 2014), it is also possible to develop rapid maps of disaster events (Ajmar et al., 2017).

3.3.2. Asset performance monitoring: An important aspect of $\mathrm{AM}$ is performance management (control, monitoring and optimization) through the whole asset life-cycle. The construction of a set of indicators, focused on the transportation system, can support the decision-making process (Chatziioannou and Álvarez-Icaza, 2017). Torres-Machi et al. (2018) proposed a GIS platform for the integration of technical, economic, environmental, social and political aspects in the life cycle assessment of a network to support the management of transportation assets. Zhang et al. (2013) developed a model to collect, manage and visualize pavement condition data; while, $\mathrm{Li}$ et al. (2018) presented a network to integrate quantitative condition data relating to crosswalks and intersections, to better manage maintenance. Different workflows and models are used to assess utility infrastructure in order to simulate deterioration and failure (Ward et al., 2017), the remaining lifecycle and the network robustness (Goyal et al., 2016).

3.3.3. Asset cost control: Cost planning and control has a fundamental role in AM. Ward et al. (2014) consider the link between investment cost and asset life cycle to evaluate potential serviceability improvements, through rehabilitation model in which GIS tools are used to identify the geospatial nature of serviceability incidents. Feliciano et al. (2014) analyse the investment payback period, Net Present Value (NPV) and energy production when valuing intervention alternatives with a hydraulic model based on GIS data.

3.3.4. Other Approaches: A number of authors propose different tools for infrastructure AM. Pfeiffer et al. (2017) developed a Grassroots Infrastructure Dependency Model (GRID-M) to enable near-real-time analysis of physical infrastructure dependencies of specific supply and demand nodes; while, Kuller et al. (2019) presented a Spatial Suitability Analysis Tool (SSANTO) to map, through "needs" and "opportunities", suitability for Water Sensitive Urban Design (WSUD) assets. 


\subsection{Integration of BIM and GIS}

The smallest number of papers $(16.6 \%)$ relates to the integration of BIM and GIS for AM. The integration of building data and geographic information is an important interoperability challenge (Ellul, 2018) and results in access to information at different scales relating to the asset and its wider context. A number of authors focused on technical problems while others analysed case studies.

3.4.1. Information Management and interoperability: Highlighting the lack of attention paid to information management over the built asset life-cycle, Hoeber and Alsem (2016) present a concept for a way of working based on the collaboration between asset managers and project managers from the start of the project and during the life-cycle of the assets, with the use of exchange standards. Guillen et al. (2016) underlined the importance of an environment of software interoperability of asset management, with the BIM model linked to other data sources, such as GIS, Building Automation Systems (BAS) and FM Systems (FMS). The conversion from BIM standard (IFC) to GIS standard (CityGML) and vice versa is not always accurate, and for this reason, a number of authors used a third-party platform to manage different data sources. Zadeh et al. (2019) presented a BIM-CityGML data integration (BCDI) approach, based on a mediated schema, with the aim to collect and manage data that can be queried simultaneously from both sources.

3.4.2. Integration and decision making: Considering transportation infrastructure, Aziz et al. (2017) proposed the use of an open-source cloud computing platform, Hadoop, to allow for continuous flow of data throughout an asset's life cycle; while, Sankaran et al. (2018) considered the potential benefit of using Civil Integrated Management (CIM), a set of practices and tools that can facilitate the workflow of highway project delivery and management. Other authors presented frameworks for utility infrastructure management: Edmondson et al. (2018) developed a prototype to aid prediction and decision making about a sewerage network; Lee et al. (2018) presented a framework, based on the integration of BIM/GIS, to improve performance of current maintenance management system; Love et al. (2018) developed a System Information Model (SIM), in which each component has geometric data (3D model), non-geometric data (type and functionality) and geographic data. The use of the SIM has different benefits (Love and Matthews, 2019), such as costsaving, improvement in information quality and in asset integrity, but it's effective if data are integrated during each phase of the life-cycle asset, from the design to the operation.

\subsection{Classification by AM Function}

The final stage of analysis relates to the analysis of the merged sample according to the core AM function and to the main asset class. Table 1 shows the results of the classification by AM function, namely the main processes implemented by an AM organisation for supporting its business. 14 core AM functions have been identified, organised according to their decisionmaking level (using an analytical approach based on that described in Re Cecconi et al. (2020), not described here for synthesis reasons). In Table 1, articles have been categorised by the type of approach addressed by the authors (BIM, GIS and BIM/GIS) and the asset class considered (Roads, Water supply networks, Electrical Energy networks etc.). This allows the identification of where the three approaches, and especially the implementation of the BIM/GIS integration, are mostly used.

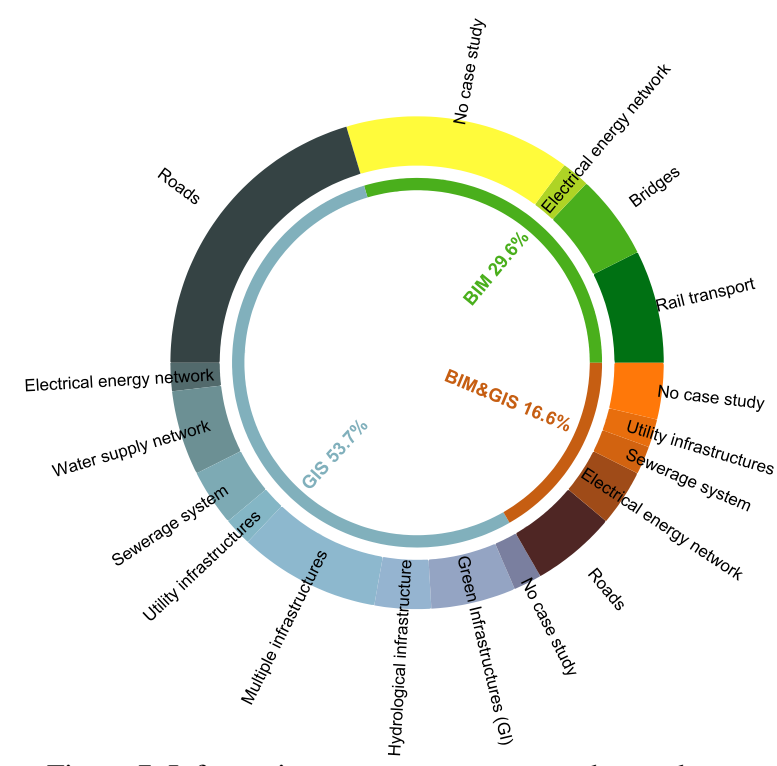

Figure 7. Information management approaches and asset classes. Each paper was counted once, and the papers focused on multiple case studies were included in the "Multiple Infrastructure" category.

\section{DISCUSSION}

The bibliometric analyses described in this paper identified the main characteristics of the literature in BIM and GIS and the integration of the two for infrastructure AM. Literature produced in the selected period shows a greater focus on GIS, especially for the strategic and tactical AM functions.

Figure 7 shows the paper count by main asset class and highlights the versatility of the GIS approach in infrastructure AM, which is also reflected by having the highest percentage of articles $(53.7 \%)$ in this group - maybe due to the long research history in GIS and the ability of this tool to manage very diverse types of data. Roads appear to be the asset class mostly addressed by case studies, along with the management of multiple infrastructures. Within the papers reviewed, a greater interest in BIM relates to AM function belonging to the tactical and operational level of the decision-making process (Facility, Project and Data Management). Also, Table 1 shows that the BIM approach has been mainly applied to the management of Bridges and Rail Transport networks, although the majority of the references do not address any specific asset class. The literature production, in this case, is smaller and accounts for the $29.6 \%$ of the total.

Articles on GIS/BIM integration are even fewer, representing $16.6 \%$ of the total. In this case, the most addressed asset classes are roads and electrical energy networks. Moreover, looking at Table 1, BIM/GIS integration research appears to be mainly focussed in the Facility and Data Management functions, again indicating a tactical/operational characterisation of this approach. However, the literature on this topic is still very recent and does not illustrate the whole potential of the BIM/GIS integrated approach for infrastructure AM.

Altogether, glancing at the asset classes addressed by the three groups of articles studied it can be stated that linear transport infrastructures (roads and railways) are the asset classes where BIM, GIS and integrated approaches have been implemented and tested the most. GIS approaches have the longest story in AM and this may lead to a wider literature on case studies implementation. However, the enhanced versatility of the GIS/BIM integrated approach may lead in the next years to the case studies development in different AM functions. 
Table 1. Articles organised by type of approach implemented by the authors and Asset Management function.

\begin{tabular}{|c|c|c|c|c|c|c|c|c|c|c|c|c|}
\hline 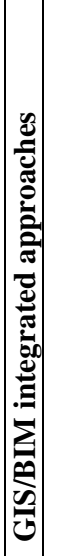 & 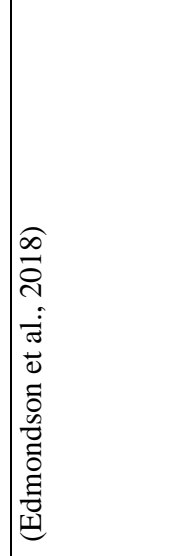 & & 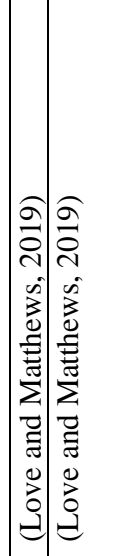 & 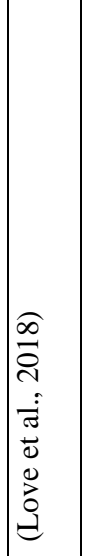 & 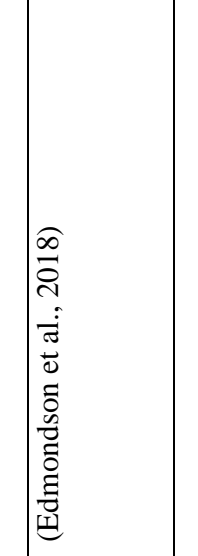 & & & 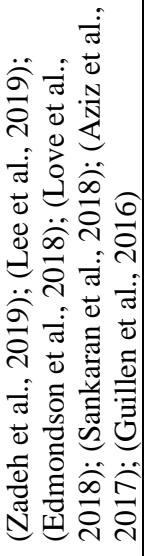 & & 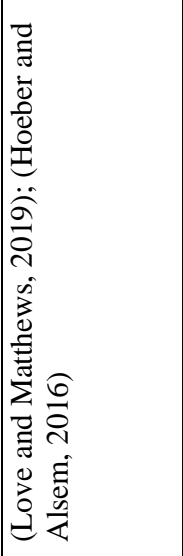 & 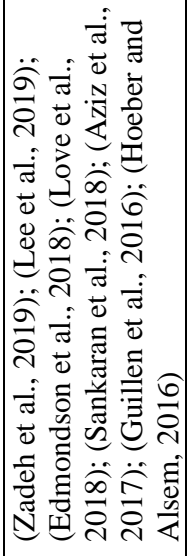 & 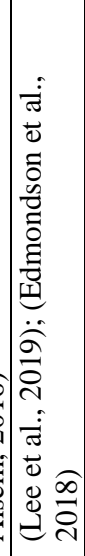 \\
\hline 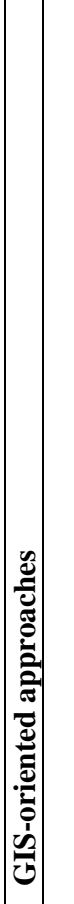 & 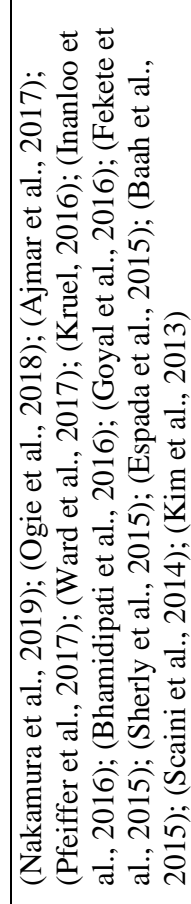 & 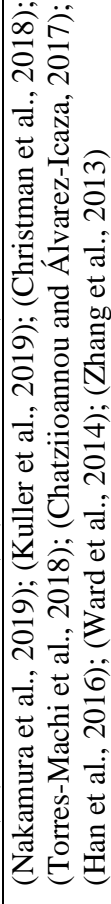 & 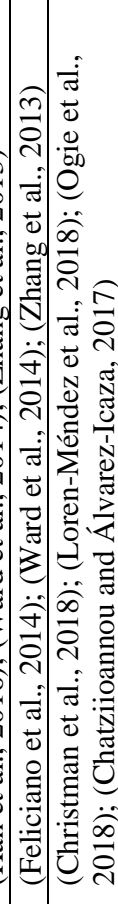 & 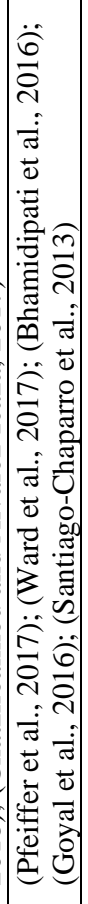 & 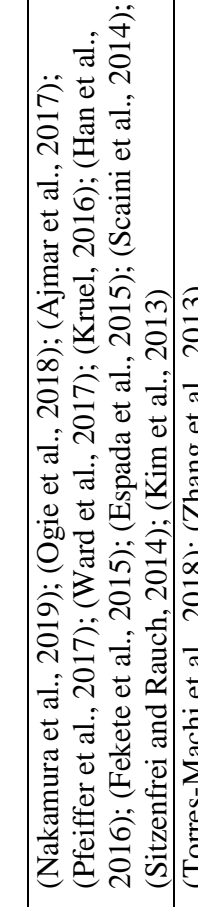 & 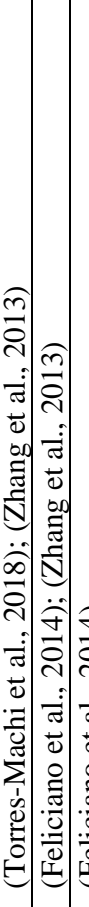 & 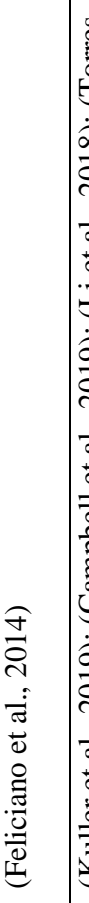 & 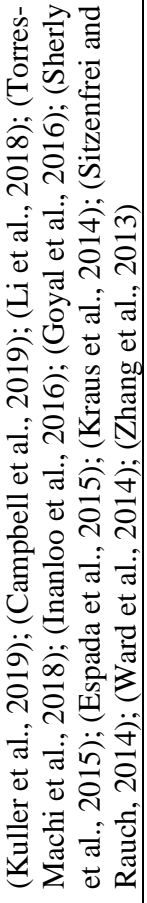 & & 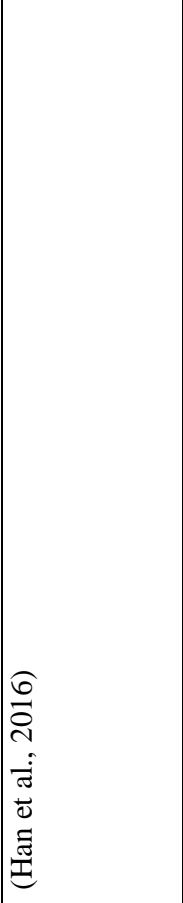 & 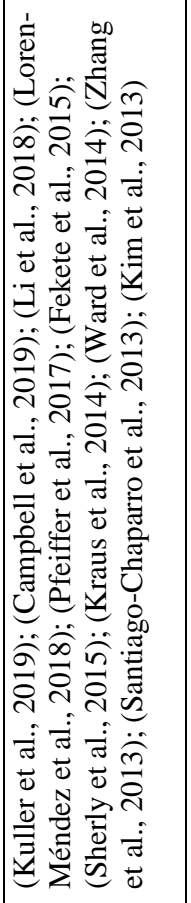 & 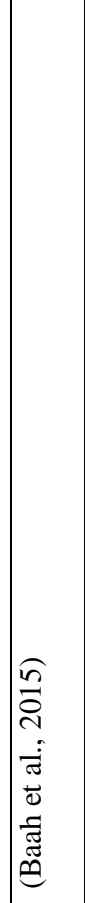 \\
\hline $\mid$ & 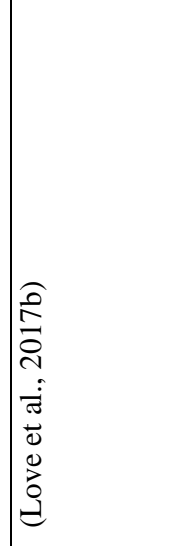 & 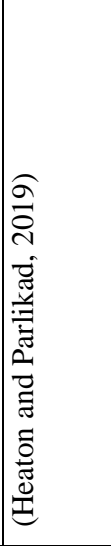 & 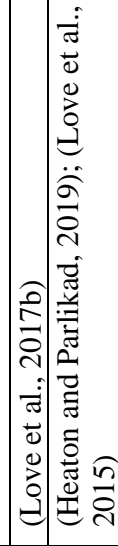 & & 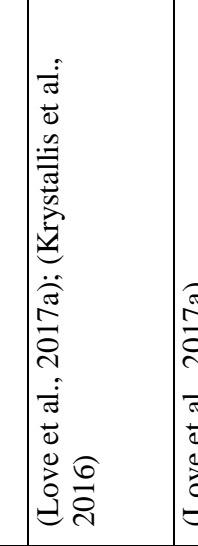 & 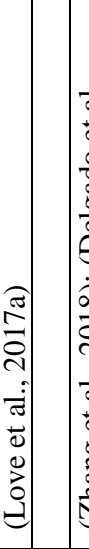 & 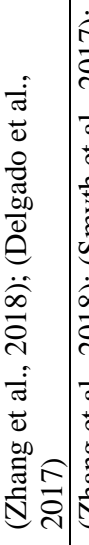 & 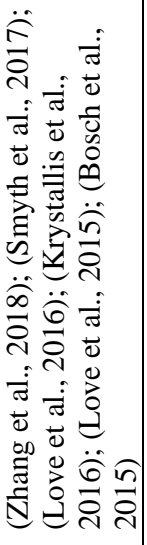 & & 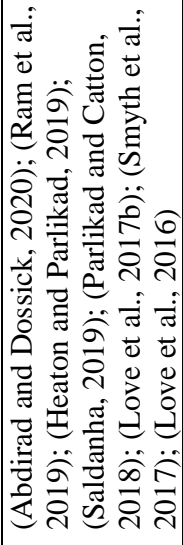 & 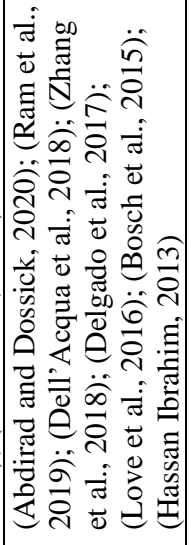 & 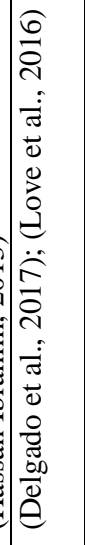 \\
\hline & $\stackrel{\infty}{\infty}$ & 1 & 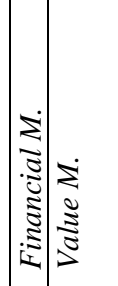 & & 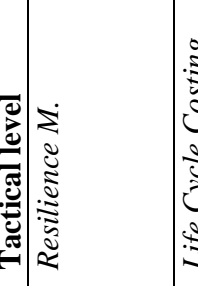 & 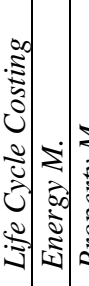 & & & 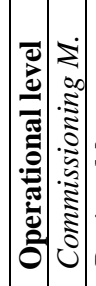 & 2 & 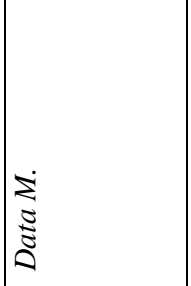 & 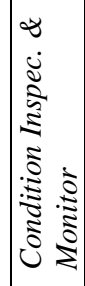 \\
\hline
\end{tabular}




\section{CONCLUSIONS}

The analyses presented in the previous paragraphs provide the basis for identifying a number of knowledge gaps that could underpin a research agenda in GeoBIM for infrastructure AM summarised in the following three groups.

Data management:

- the production of data is often an onerous process and does not always provide quality outcomes as updated and sound as-built models;

- as-built models are seldom available, although they would allow the preservation of a significant amount of data to be employed in the following stage of the integration and use of the asset; and

- data are not always reliable and accurate, therefore a deeper attention to data quality is required.

Interoperability and integration:

- software interoperability is rarely possible for operations with available data in infrastructure AM. There is a big issue relating to the BIM/GIS data exchange: typically, between IFC to CityGML format. Standardised procedures should be defined to further automate the information exchange; and

- there is a serious issue relating to integration of the existing information management systems, employed for AM, with the GeoBIM approach.

Process and service management:

- although literature is limited, advantages of the BIM/GIS integration have been addressed in Facility and Data management. However, coupling the potential of BIM and GIS could leverage strategic and tactical/operational features of the two approaches;

- detailed information and geometric modelling capabilities of BIM and advanced data integration and the management potential of GIS could be leveraged in AM functions where multi-scale and cross-disciplinary problems arise, such as Risk and Resilience Management;

- enhanced interoperability and data management capabilities could improve Condition Inspection \& Monitoring, Facility Management and Life Cycle Costing operations;

- system scalability and, again, data management capabilities can be harnessed for Energy Management; and

- as result of the literature critical review, BIM and GIS individually demonstrate effective tools for AM of linear infrastructure. A fruitful asset class on which to test the BIM/GIS integration potential might be Railways, where to date no references can be found.

These issues - which developed specifically with a GeoBIM/AM/Infrastructure context - reflect those encountered in wider GeoBIM research (Ellul, 2018), perhaps renewed additionally complex due to the addition of AM into the mix. A collaborative effort towards their resolution - to the benefit of the wider GeoBIM community - is certainly to be encouraged.

\section{ACKNOWLEDGEMENTS}

The authors would like to thank Ordnance Survey GB (https://www.ordnancesurvey.co.uk) and 1Spatial (https://1spatial.com/) for sponsoring the publication of this paper.

\section{REFERENCES}

Abdirad, H., Dossick, C.S., 2020. Rebaselining Asset Data for Existing
Facilities and Infrastructure. J. Comput. Civ. Eng. 34.

Ajmar, A., Boccardo, P., Broglia, M., Kucera, J., Giulio-Tonolo, F., Wania, A., 2017. Response to Flood Events: The Role of Satellite-based Emergency Mapping and the Experience of the Copernicus Emergency Management Service, in: Molinari, D. et al. (Eds.), Flood Damage Survey and Assessment: New Insights from Research and Practice, Geophysical Monograph Book Series. AGU, Washington DC (USA), pp. 213-228.

Amadi-Echendu, J.E., Willett;, K.B.R., Mathew, J., Editors, 2010. Definitions Concepts and Scope of Engineering Asset Management.

Aria, M., Cuccurullo, C., 2017. bibliometrix: An R-tool for comprehensive science mapping analysis. J. Informetr. 11, 959-975.

Aziz, Z., Riaz, Z., Arslan, M., 2017. Leveraging BIM and Big Data to deliver well maintained highways. Facilities 35, 818-832.

Baah, K., Dubey, B., Harvey, R., McBean, E., 2015. A risk-based approach to sanitary sewer pipe asset management. Sci. Total Environ. 505, 1011-1017.

Bhamidipati, S., van der Lei, T., Herder, P., 2016. A layered approach to model interconnected infrastructure and its significance for asset management. Eur. J. Transp. Infrastruct. Res. 16, 254-272.

Bishop, W., Grubesic, T.H., 2016. Geographic information, maps, and GIS, in: Springer Geography. Springer, pp. 11-25.

Bosch, A., Volker, L., Koutamanis, A., 2015. BIM in the operations stage: Bottlenecks and implications for owners. Built Environ. Proj. Asset Manag. 5, 331-343.

BSI, 2018. BIM - Building Information Modeling Certification | BSI Group. URL https://www.bsigroup.com/en-GB/Building-InformationModelling-BIM/ (accessed 4.1.20).

Campbell, A., Both, A., Sun, Q.C., 2019. Detecting and mapping traffic signs from Google Street View images using deep learning and GIS. Comput. Environ. Urban Syst. 77.

Chatziioannou, I., Álvarez-Icaza, L., 2017. Evaluation of the urban transportation infrastructure and its urban surroundings in the Iztapalapa County: A geotechnology approach about its management. Cogent Eng. 4.

Christman, Z., Meenar, M., Mandarano, L., Hearing, K., 2018. Prioritizing Suitable Locations for Green Stormwater Infrastructure Based on Social Factors in Philadelphia. Land 7.

Delgado, J.M.D., and other 5, 2017. Management of structural monitoring data of bridges using BIM. Proc. Inst. Civ. Eng. Bridg. Eng. 170, 204-218.

Dell'Acqua, G., De Oliveira, S.G., Biancardo, S.A., 2018. Railway-BIM: Analytical review, data standard and overall perspective. Ing. Ferrov. 73, 901-923.

Dixit, M.K., and other 4, 2019. Integration of facility management and building information modeling (BIM): A review of key issues and challenges. Facilities 37, 455-483.

Edmondson, V., and other 5, 2018. A smart sewer asset information model to enable an 'Internet of Things' for operational wastewater management. Autom. Constr. 91, 193-205.

Ellul, C., Stoter, J., Harrie, L., Shariat, M., Behan, A., Pla, M., 2018 Investigating the state of play of GeoBIM across Europe. ISPRS - Int Arch. Photogramm. Remote Sens. Spat. Inf. Sci. XLII-4/W10, 19-26.

Espada, R.J., Apan, A., McDougall, K., 2015. Vulnerability assessment and interdependency analysis of critical infrastructures for climate adaptation and flood mitigation. Int. J. Disaster Resil. Built Environ. 6, 313-346.

ESRI, 2020. What is GIS? | Geographic Information System Mapping Technology. URL https://www.esri.com/en-us/what-is-gis/overview (accessed 4.1.20).

Fekete, A., Tzavella, K., Armas, I., Binner, J., Garschagen, M., Giupponi, C., Mojtahed, V., Pettita, M., Schneiderbauer, S., Serre, D., 2015. Critical data source; Tool or even infrastructure? Challenges of geographic information systems and remote sensing for disaster risk governance. ISPRS Int. J. Geo-Inf. 4, 1848-1869.

Feliciano, J., and other 5, 2014. Energy efficiency in water distribution systems 'a path to an ideal network: AGS experience. Water Sci. Technol. Water Supply 14, 708-716.

Goyal, A., Aprilia, E., Janssen, G., Kim, Y., Kumar, T., Mueller, R., Phan, D., Raman, A., Schuddebeurs, J., Xiong, J., Zhang, R., 2016. Asset health management using predictive and prescriptive analytics for the electric power grid. IBM J. Res. Dev. 60.

Guillen, A.J., Crespo, A., Gómez, J., González-Prida, V., Kobbacy, K., 
Shariff, S., 2016. Building Information Modeling as Assest Management Tool. IFAC-PapersOnLine 49, 191-196.

Han, H., Chung, W., Song, J., Seol, A., Chung, J., 2016. A terrain-based method for selecting potential mountain ridge protection areas in South Korea. Landsc. Res. 41, 906-921.

Hassan Ibrahim, N., 2013. Reviewing the evidence: USE of digital collaboration technologies in major building and infrastructure projects. J. Inf. Technol. Constr. 18, 40-63.

Heaton, J., Parlikad, A.K., 2019. A conceptual framework for the alignment of infrastructure assets to citizen requirements within a Smart Cities framework. CITIES 90, 32-41.

Hoeber, H., Alsem, D., 2016. Life-cycle information management using open-standard BIM. Eng. Constr. Archit. Manag. 23, 696-708.

Inanloo, B., and other 4, 2016. A decision aid GIS-based risk assessment and vulnerability analysis approach for transportation and pipeline networks. Saf. Sci. 84, 57-66.

ISO, 2018a. EN ISO 19650-1:2018. Organization and digitization of information about buildings and civil engineering works, including BIM - Information management using BIM. Part 1: Concepts and principles. ISO, 2018b. EN ISO 19650-2:2018. Organization and digitization of information about buildings and civil engineering works, including BIM - Information management using BIM. Part 2: Delivery phase of the a.

ISO, 2014. ISO 55000:2014 Asset management Overview, principles and terminology.

Kim, K., Pant, P., Yamashita, E., 2013. Using national household travel survey data for the assessment of transportation system vulnerabilities. Transp. Res. Rec. 71-80.

Kraus, E., Quiroga, C., Le, J., 2014. Strategies to optimize the management of right-of-way parcel and utility information. Transp. Res. Rec. 2436, 119-128.

Kruel, S., 2016. The Impacts of Sea-Level Rise on Tidal Flooding in Boston, Massachusetts. J. Coast. Res. 32, 1302-1309.

Krystallis, I., and other 3, 2016. Future-proofing governance and BIM for owner operators in the UK. Infrastruct. ASSET Manag. 3, 12-20.

Kuller, M., Bach, P.M., Roberts, S., Browne, D., Deletic, A., 2019. A planning-support tool for spatial suitability assessment of green urban stormwater infrastructure. Sci. Total Environ. 686, 856-868.

Lee, P.-C., Wang, Y., Lo, T.-P., Long, D., 2019. An integrated system framework of building information modelling and geographical information system for utility tunnel maintenance management (vol 79, pg 263, 2018). Tunn. Undergr. Sp. Technol. 83, 592.

Li, H., and other 5, 2018. A Semi-Automated Method to Generate GISBased Sidewalk Networks for Asset Management and Pedestrian Accessibility Assessment. Transp. Res. Rec. 2672, 1-9.

Loren-Méndez, and other 3, 2018. Mapping heritage: Geospatial online databases of historic roads. The case of the N-340 roadway corridor on the Spanish mediterranean. ISPRS Int. J. Geo-Information 7.

Love, P.E.D., Ahiaga-Dagbui, D., Welde, M., Odeck, J., 2017a. Light rail transit cost performance: Opportunities for future-proofing. Transp. Res. PART A-POLICY Pract. 100, 27-39.

Love, P.E.D., Liu, J., Matthews, J., Sing, C.P., Smith, J., 2015. Future proofing PPPs: Life-cycle performance measurement and Building Information Modelling. Autom. Constr. 56, 26-35.

Love, P.E.D., Matthews, J., 2019. The 'how' of benefits management for digital technology: From engineering to asset management. Autom. Constr. 107.

Love, P.E.D., Zhou, J., Edwards, D.J., Irani, Z., Sing, C.-P., 2017b. Off the rails: The cost performance of infrastructure rail projects. Transp. Res. PART A-POLICY Pract. 99, 14-29.

Love, P.E.D., Zhou, J., Matthews, J., Lavender, M., Morse, T., 2018. Managing rail infrastructure for a digital future: Future-proofing of asset information. Transp. Res. Part A Policy Pract. 110, 161-176.

Love, P.E.D., Zhou, J., Matthews, J., Luo, H., 2016. Systems information modelling: Enabling digital asset management. Adv. Eng. Softw. 102, 155-165.

Moher, D., and other 8, 2015. Preferred reporting items for systematic review and meta-analysis protocols (PRISMA-P) 2015 statement. Syst. Rev. 4, 1.

Nakamura, F., Ishiyama, N., Yamanaka, S., Higa, M., Akasaka, T., Kobayashi, Y., 2019. Adaptation to climate change and conservation of biodiversity using green infrastructure. RIVER Res. Appl.

Noardo, F., and other six, 2019. EUROSDR Geobim Project A Study In
Europe On How To Use The Potentials Of Bim And Geo Data In Practice. ISPRS - Int. Arch. Photogramm. Remote Sens. Spat. Inf. Sci. XLII-4/W15, 53-60.

Ogie, R.I., Holderness, T., Dunn, S., Turpin, E., 2018. Assessing the vulnerability of hydrological infrastructure to flood damage in coastal cities of developing nations. Comput. Environ. URBAN Syst. 68, 97-109.

Parlikad, A.K., Catton, P., 2018. Infrastructure information management of bridges at local authorities in the UK. Infrastruct. Asset Manag. 5, 120131.

Parn, E.A., Edwards, D., 2019. Cyber threats confronting the digital built environment: Common data environment vulnerabilities and block chain deterrence. Eng. Constr. Archit. Manag. 26, 245-266.

Pfeiffer, K.B., Burdi, C., Schlueter, S., 2017. Local supply chains: The disaster management perspective. Int. J. Saf. Secur. Eng. 7, 399-405.

Ram, J., Afridi, N.K., Khan, K.A., 2019. Adoption of Big Data analytics in construction: development of a conceptual model. Built Environ. Proj. Asset Manag. 9, 564-579.

Re Cecconi, F., Dejaco, M.C., Moretti, N., Mannino, A., Blanco Cadena, J.D., 2020. Digital asset management, in: Research for Development. Springer, pp. 243-253.

Saldanha, A.G., 2019. Applications of building information modelling for planning and delivery of rapid transit. Proc. Inst. Civ. Eng. Munic. Eng. 172, 122-132.

Sankaran, B., Nevett, G., O'Brien, W.J., Goodrum, P.M., Johnson, J., 2018. Civil Integrated Management: Empirical study of digital practices in highway project delivery and asset management. Autom. Constr. 87, 84-95.

Santiago-Chaparro, K.R., Chitturi, M., Bill, A., Noyce, D.A., 2013. Automatic network-level identification of sight distance values from existing datasets. Transp. Lett. 5, 1-6.

Saxon, R., Robinson, K., Winfield, M., 2018. Going Digital. A guide for construction clients, building owners and their advisers.

Scaini, C., and other 3, 2014. A GIS-based methodology for the estimation of potential volcanic damage and its application to Tenerife Island, Spain. J. Volcanol. Geotherm. Res. 278-279, 40-58.

Sherly, M.A., and other 4, 2015. Disaster Vulnerability Mapping for a Densely Populated Coastal Urban Area: An Application to Mumbai, India. Ann. Assoc. Am. Geogr. 105, 1198-1220.

Sitzenfrei, R., Rauch, W., 2014. Integrated hydraulic modelling of water supply and urban drainage networks for assessment of decentralized options. Water Sci. Technol. 70, 1817-1824.

Smyth, H., Anvuur, A.M., Kusuma, I., 2017. Integrated solutions for total asset management through "RIVANS". BUILT Environ. Proj. ASSET Manag. 7, 5-18.

Torres-Machi, C., and other 5, 2018. Sustainable Management Framework for Transportation Assets: Application to Urban Pavement Networks. KSCE J. Civ. Eng. 22, 4095-4106.

Ward, B., Kawalec, M., Savić, D., 2014. An optimised total expenditure approach to sewerage management. Proc. Inst. Civ. Eng. Munic. Eng. 167, 191-199.

Wang, H. P. (2019). Integration of BIM and GIS in sustainable built environment: A review and bibliometric analysis. Autom. Constr. 103, pp.41-52.

Ward, B., Selby, A., Gee, S., Savic, D., 2017. Deterioration modelling of small-diameter water pipes under limited data availability. Urban Water J. 14, 743-749.

Zadeh, P.A., Wei, L., Dee, A., Pottinger, R., Staub-French, S., 2019. BIM-CITYGML data integration for modern urban challenges. J. Inf. Technol. Constr. 24, 318-340.

Worboys, M. a. (2004). GIS: a computing perspective. CRC press.

Zhang, H., Keoleian, G.A., Lepech, M.D., 2013. Network-level pavement asset management system integrated with life-cycle analysis and lifecycle optimization. J. Infrastruct. Syst. 19, 99-107.

Zhang, Z., Hamledari, H., Billington, S., Fischer, M., 2018. 4D beyond construction: Spatio-temporal and life-cyclic modeling and visualization of infrastructure data. J. Inf. Technol. Constr. 23, 285-304.

Zhao, L., Liu, Z., Mbachu, J., 2019. Highway alignment optimization: An integrated BIM and GIS approach. ISPRS Int. J. Geo-Information. 8. 